\title{
Modelo de control constitucional a posteriori de la ley en Chile a doce años de la Reforma Constitucional. Ley $\mathbf{N}^{\circ} \mathbf{2 0 . 0 5 0}$ de $2005^{1}$
}

\author{
Model of constitutional control after the law in Chile \\ to 12 years of the Constitutional Reform. Law $N^{\circ}$ \\ 20.050 of 2005
}

\section{Emilio Alfonso Garrote Campillay ${ }^{2}$ \\ Universidad de Atacama emilio.garrote@uda.cl}

\begin{abstract}
Resumen: En este trabajo se estudia descriptivamente el sistema de control de constitucionalidad de la ley introducido por la reforma Constitucional, Ley $\mathrm{N}^{\circ} 20.050$ de 26 de agosto de 2005, consagrado en el artículo 93 N $^{\circ} 6$ y 7 de la Constitución Política de la República de 1980, a través de un análisis teórico y comparado; a objeto de determinar el modelo de control constitucional a posteriori de la ley implementado por el constitu-
\end{abstract}

1 Agradezco especialmente al profesor Dr. José Ignacio Martínez Estay sus aclaraciones y consejos en la preparación de este artículo.

2 Abogado, Doctor en Derecho y Magister en Derecho Público por la Universidad de los Andes, Santiago de Chile. Profesor Asistente de Derecho Constitucional, Derecho Administrativo y Teoría del Estado. Facultad de Ciencias Jurídicas y Sociales. Departamento de Ciencias Jurídicas. Carrera de Derecho. Universidad de Atacama. Dirección Postal: Avenida Copayapu 485, Copiapó, Chile. 
yente derivado. El tema a tratar es de real importancia y contingencia ya que estamos hablando del sistema de defensa de la Constitución. Los resultados del estudio demuestran que el constituyente derivado de 2005 se apartó de los modelos clásicos de control constitucional, esto es, difuso y concentrado optando por un sistema particular y único. Dicho modelo no es difuso ni es concentrado, sino confuso, por lo que lo he calificado como un sistema hibrido. Ello porque es difuso en la base pero concentrado en la cima, esencialmente concreto, aunque no está cerrado o a lo menos no lo cierra el Tribunal Constitucional. Lo que implica apartarse de los modelos tradicionales sobre la materia y de las posiciones doctrinales y jurisprudenciales existentes a este respecto a nivel nacional y en la legislación comparada. Se debe dejar expresa constancia que en el trabajo no se aborda el control preventivo o a priori que realiza el Tribunal Constitucional $^{3}$. En el mismo sentido, tampoco se aborda el control que realiza el órgano constitucional respecto de otros actos normativos y demás funciones de competencia del Tribunal Constitucional Chileno.

Palabras clave: Modelos de Control de Constitucionalidad de la Ley, interpretación y aplicación, inaplicabilidad e inconstitucionalidad

Abstract: In this paper, the constitutional control system of the law introduced by the Constitutional reform, Law N ${ }^{\circ} 20.050$ of August 26, 2005, twelve years after the reform, enshrined in article $93 \mathrm{~N}^{\circ} 6$ and 7 of the Political Constitution of the Republic of 1980, through a theoretical and comparative analysis; in order to determine the model of constitutional control aposteriori of the law implemented by the constituent derived from the law of constitutional reform in comment. The issue to be discussed is of real importance and contingency since we are talking about the defense system of the Constitution. The results of the study show that the constituent derived from 2005 departed from the classical models of constitutional control, that is, diffuse and concentrated opting for a particular and unique system. This model is not diffuse or concentrated, but confusing, so I have classified it as a hybrid system. This is because it is diffuse in the base but concentrated in the summit, essentially concrete, although it is not closed or at least it is not closed by the Constitutional Court. What implies

3 Sobre el particular véase entre otros, VeRdugo (2010), p 201 y ss. 
to depart from the traditional models on the subject and the existing doctrinal and jurisprudential positions in this regard at the national level and in comparative legislation. It must be expressly stated that the work does not address the preventive or a priori control that the TCC performs. In the same sense, the control carried out by the constitutional body with respect to other normative acts and other functions of competence of the Chilean Constitutional Court is also not addressed.

Keywords: Control Models of the Constitutionality of the Law, interpretation and application, inapplicability and unconstitutionality

\section{Introducción}

La Constitución de 1980 consagró al Tribunal Constitucional (en adelante TCCh), como guardián de la Constitución (en adelante CPRCh). Es decir, su misión o finalidad es velar y asegurar la supremacía constitucional mediante el control de los actos de los poderes públicos, en particular del legislativo y del ejecutivo a objeto de evitar que éstos atenten contra las disposiciones y principios consagrados en la Ley Fundamental. Así se siguió la tendencia mundial de la época, en especial en Europa después de la segunda guerra, de crear órganos especializados en la defensa de la Constitución.

Si el sistema de defensa de la Constitución Chilena antes de 2005 ya era complejo, hoy en día lo es aún más, pero también es novedoso. Ello porque el sistema control chileno presenta características y particularidades que no se observan en la legislación comparada, por lo que lo hacen un sistema único y especial, distinto a los demás, Francia, España, Alemania, Italia, Portugal ${ }^{4}$. En particular el diseño del requerimiento de

4 La Constitución portuguesa de 1976 al respecto señala que "En los hechos sometidos a enjuiciamiento no podrán los Tribunales aplicar normas inconstitucionales, y tendrán con objeto, y sin perjuicio de lo dispuesto en el artículo 282, la facultad de apreciar la existencia de inconstitucionalidad". Esto es, el constituyente derivado prohíbe expresamente a los jueces aplicar normas inconstitucionales. En otras palabras, y lo que es lo mismo, establece un sistema de control constitucional de carácter difuso, otorgándoles expresamente la facultad de declarar la inconstitucionalidad de todas aquellas normas contraria a la Constitución. Constitución Portuguesa (1976), artículo 202. Examen de Inconstitucionalidad. 
la inaplicabilidad como presupuesto de la acción o cuestión de inconstitucionalidad o la posibilidad tanto del juez como de las partes del caso sub lite de recurrir directamente ante el órgano de control constitucional, entre otras.

El tema tampoco ha sido abordado en su real dimensión por la doctrina nacional. Lo cual reafirma la importancia, originalidad e interés del mismo. Sin desconocer y mucho menos desmerecer los aportes que sobre la materia ha realizado la doctrina nacional, estimo que éstos no se corresponden con la realidad existente en nuestro sistema constitucional. Los esfuerzos en su gran mayoría han sido encaminados en determinar los efectos de las sentencias constitucionales tanto en el ámbito de la inaplicabilidad como en el de la inconstitucionalidad ${ }^{5}$ partiendo de la premisa que la Ley de reforma constitucional $\mathrm{N}^{\circ} 20.050$ estableció un sistema de control constitucional de carácter concentrado ${ }^{6}$, sin entrar a explicitar de que estamos hablando o que se entiende que un sistema sea concentrado, salvo contadas excepciones de las cuales el trabajo da cuenta.

La anterior, es la opinión mayoritaria de la doctrina nacional. Ésta asume que el constituyente derivado concentro las competencias en materia de control constitucional en el TCCh, y que por lo tanto se trataría de un modelo concentrado sin entrar a explicar que es lo que entienden por un sistema concentrado de justicia constitucional como si todos estuviéramos de acuerdo en ello.

Asimismo debe tenerse presente que esta investigación arranca de ciertos supuestos que se ha estimado necesario explicitarlos. Estos dicen relación con el concepto de Derecho y de Constitución, respecto de los cuales ya lo he señalado en otros trabajos ${ }^{7}$. Por otra parte, debe considerarse que a lo largo de la investigación se han hecho una serie de opciones, en temáticas en las que cabe más de una posición. Así por ejemplo, prefiero utilizar la expresión justicia constitucional y no jurisdicción

5 Véase entre otros, Garrote (2012), p. 394; Saenger (2007), p.309; ZúNíiga y Vega (2006), p.146; Couso y Coddou (2010), p. 394.

6 Véase entre otros CeA (2005), pp. 67-72; Colombo (2005), p. 585, Ríos (2002), p. 389

7 GarRote (2017), p 14 y ss. 
constitucional, en el entendido que existen otros órganos y diversas vías a través de las cuales también se defiende la supremacía constitucional, y se determina el alcance y sentido de los preceptos constitucionales. Los que sólo se mencionan a manera referencial. Ello porque, como ya se anticipó, el objeto de estudio se centra en la determinación del sistema de control de constitucionalidad de la ley a posteriori o represivo contenido en los números 6 y 7 del artículo 93 de la CPRCh.

\section{Defensa de la Constitución: Justicia Constitucional - Jurisdicción Constitucional}

El primer aspecto a considerar en este apartado es el relativo a cómo debemos referirnos al hablar del control de constitucionalidad de la ley aposteriori ¿Debe hablarse de justicia constitucional o de jurisdicción constitucional? La pregunta es relevante en un sistema jurídico como el chileno en el que conviven una jurisdicción ordinaria y otra de carácter especializado en lo constitucional. Ello sin perjuicio de que, como ocurre también en otros países, hay órganos no judiciales que también cumplen un rol de control de juridicidad que incluye a la Constitución, como ocurre en Chile con la Contraloría General de la República. La aplicación de la Constitución es realizada tanto por la jurisdicción constitucional (Tribunal Constitucional) como por la jurisdicción ordinaria. Ambas aplican e interpretan la Constitución, ambas deben interpretar constitucionalmente la ley, y ambas pueden enjuiciar la conformidad a la Norma Fundamental de los actos sometidos a su control jurisdiccional.

\subsection{Justicia constitucional}

Tradicionalmente la justicia constitucional se entendía como un concepto formal. Durante gran parte del siglo XX ésta era la justicia constitucional concentrada, diseñada de acuerdo, más o menos, con el modelo Kelseniano de la década de los años 20, plasmada originariamente en las constituciones checa y, sobre todo austriaca, y por tanto residía en un órgano ad hoc, en contraste con el otro modelo de control de constitucionalidad de las leyes, el difuso norteamericano o de judicialreview, 
consagrado en Estados Unidos por el juez Marshall desde la sentencia Marbury v/s. Madison en 1803 a partir de los precedentes de control de constitucionalidad de leyes estatales.

En palabras de Aragón Reyes, la justicia constitucional ${ }^{8}$ bajo el modelo europeo es entendida como aplicación judicial de la Constitución. Es ejercida por ambas jurisdicciones, tanto por la constitucional como por la jurisdicción ordinaria, ambas aplican e interpretan la Constitución, ambas deben interpretar constitucionalmente la ley, y ambas pueden enjuiciar la conformidad a la Norma Fundamental de los actos sometidos a su control jurisdiccional ${ }^{9}$. En cambio la denominación jurisdicción constitucional normalmente se aplica al Tribunal Constitucional ${ }^{10}$. Para Bordalí Salamanca, "se trata que órganos judiciales puedan controlar al poder del Estado para salvaguardar la libertad de los ciudadanos y el respeto de las reglas del juego democrático constitucionalmente establecidas"11.

La denominación justicia constitucional resulta ser una expresión más apropiada si se considera el término justicia como sinónimo de judicial. Pero además permite considerar el carácter axiológico que estos instrumentos pueden tener, lo que permitiría incluir algunos otros instrumentos u organismos que también participan en la tarea de interpretación y aplicación de la Constitución. Tal sería el caso del Ombudsman escandinavo, el Consejo Constitucional Francés, la Contraloría General de la República y Tribunales Ordinarios en el caso chileno. Desde un punto de vista procesal una y otra jurisdicción conocen de manera exclusiva los procesos que les han sido atribuidos. Pero desde el punto de vista material, esto es, el ejercicio de la justicia constitucional ${ }^{12}$, ambas jurisdicciones confluyen en su actividad. Sin embargo, hay que tener presente que en esta materia la jurisdicción constitucional es suprema, y tiene el monopolio de la invalidación de las leyes, resultando cuestionable el carácter de

8 Pérez (2003), p. 2.

9 Aragón (2007), p. 31 ss.

10 Corzo (1993), p. 864.

11 Bordalí (2003), p. 285.

12 Mezzetti (2009), p.281 y ss; Bordalí (2003), p. 285 ss.; Capelletti, (1960); Cartabia (2007); Cea (1993); Cea (2001); Celotto (2006). 
suprema ${ }^{13}$.

Para concluir, sólo diré que he preferido utilizar el concepto de justicia constitucional, el cual en mi opinión resulta más apropiado dadas las características y particularidades del modelo de control constitucional que se analizará, y como se tendrá la ocasión de ver, en la interpretación y aplicación de las normas constitucionales no hay exclusividad jurisdiccional. Muy por el contrario, en algunos casos hay superposición de jurisdicciones. Salvo el caso de Alemania, donde el Tribunal Constitucional Federal forma parte del Poder Judicial y es el máximo órgano del mismo, concentrando el control constitucional de la ley En tanto en Italia, Francia, Portugal y España, cuyos Tribunales Constitucionales están fuera del Poder Judicial hay una convivencia permanente entre las judicaturas.

\subsection{Control constitucional}

El control constitucional es una consecuencia jurídica de una cualidad también jurídica de la Constitución, a saber, su carácter de supralegal. Implica la facultad de los magistrados de comparar una norma dictada por el poder político -legislativo o ejecutivo- con normas de jerarquía superior, para hacer prevalecer a éstas sobre aquellas ${ }^{14}$.

a) Control Político. Hablamos de control político en aquellos sistemas donde el control de la ley lo realiza directa o indirectamente el poder legislativo o el ejecutivo, por ejemplo, el Consejo Constitucional francés establecido en 1958. Así se dice que, Francia no tiene o no tenía control jurisdiccional al igual que Inglaterra. Así se ha afirmado que en Francia tienen control político e Inglaterra no tendría judicial review, y el control del Parlamento de Westminter sobre la conformidad de la ley a los principios del common law no se considera político ${ }^{15}$.

b) Control Jurídico. Por su parte el control jurídico es el conjunto de recursos jurídicos diseñados para verificar la correspondencia entre los actos emitidos por quienes decretan el poder y la Constitución, anulándo-

13 Silva (2012), pp. 573 y ss; ARAgón (2005).

14 De Stefano (2005), p.1.

15 Pegoraro (2019), p. 43 ss. 
los cuando aquellos quebrantan los principios constitucionales. El fundamento de este control es el mantenimiento del Principio de Supremacía Constitucional ${ }^{16}$.

Así, el legislador crea el ordenamiento jurídico, mientras que la jurisdicción lo tutela, la administración es dependiente y actúa en el cauce de su discrecionalidad; la jurisdicción es independiente y su actividad se ve constreñida por restricciones legales; la jurisdicción actúa cuando se ha vulnerado el ordenamiento y alguien solicita su restablecimiento; las sentencias judiciales a diferencia de las leyes o actos administrativos, no se pueden anular por actos legislativos o administrativos, la independencia e imparcialidad son características sobresalientes de la jurisdicción.

En el Derecho comparado existen diversos sistemas de aplicación. Así, encontramos el control político ${ }^{17}$ y el control judicial ${ }^{18}$, y dentro de este último tenemos el control judicial concentrado ${ }^{19} \mathrm{y}$ el control judicial difuso $^{20}$. Para los efectos de la presente investigación nos interesa el control jurídico.

\section{Modelo de control constitucionalidad a posteriori de la Ley en Chile}

Al hablar de control de constitucionalidad se está haciendo referencia al mecanismo jurídico establecido por la propia Constitución para su defensa, y que se basa de manera directa en el principio de supremacía constitucional e indirectamente en la tutela de derechos fundamentales ${ }^{21}$. Constituye así una garantía de la supremacía y vinculación directa de la Constitución ${ }^{22}$.

16 COVIAN (2013), p. 28.

17 El control lo realiza directa o indirectamente el Poder Legislativo o el Poder Ejecutivo, por ejemplo el Consejo Constitucional Francés establecido en 1958.

18 En este caso la atribución descansa en los órganos jurisdiccionales.

19 El control es ejercido por órganos especializados en temas constitucionales, que pueden pertenecer o no al Poder Judicial.

20 Acá la atribución de control es entregada en general al Poder Judicial, independiente de su fuero o jurisdicción.

21 “(...) También protege los derechos fundamentales, pero va a protegerlos limitando a los poderes del Estado". FAVOREu (1998-1999), p. 15.

22 “(...) la importancia que tiene la temática de la defensa de la Constitución, para estar en po- 
En Chile existen tres vías para la defensa de la Constitución. Una primera vía de naturaleza estrictamente jurisdiccional, a cargo de todos los tribunales ordinarios a través de la acción de nulidad de derecho público, Cortes de Apelaciones y la Corte Suprema a través de la acción de protección y de amparo y los tribunales especiales. Una segunda vía de naturaleza administrativa, a cargo de la Contraloría General de la República, y una tercera vía constituida por la jurisdicción especial constitucional a cargo de un organismo autónomo e independiente denominado Tribunal Constitucional. Desde un punto de vista procesal una y otra jurisdicción conocen de manera exclusiva los procesos que les han sido atribuidos, pero desde el punto de vista material, esto es, ejercicio de la justicia constitucional ${ }^{23}$, ambas jurisdicciones confluyen en su actividad. Sin embargo, hay que tener presente que en esta materia la jurisdicción constitucional pareciera tener primacía, por ser especializada ${ }^{24}$.

Para los efectos de esta investigación interesa el sistema de control de constitucionalidad de la ley que efectúa a posteriori el Tribunal Constitucional en virtud de la acción de inaplicabilidad y la cuestión de inconstitucionalidad, establecidas en el artículo 93 números 6 y 7 de la CPRCh. Advierto desde ya que no hay unanimidad en la doctrina nacional sobre el tema, aunque hay que reconocer que hoy hay un mayor consenso que el sistema actual sería más bien concentrado, lo que como se verá más adelante, resulta al menos discutible ${ }^{25}$.

Favoreu al definir que entiende por Tribunal constitucional, conceptualiza el sistema de control constitucional concentrado: "un Tribunal constitucional es una jurisdicción creada para conocer especial y exclusivamente en materia de lo contencioso constitucional, situada fuera del aparato jurisdiccional ordinario e independiente tanto de éste como de

sibilidades de armar un constructo teórico que nos permita afirmar que la justicia constitucional es una obligación de todos los órganos del Estado". URIBE (2006), p.120.

23 Mezzetti (2009), p. 281 ss.; Bordali (2003), p. 285 ss.; Capelletti (2007), p. 41 ss.; Cartabia (2007), pp.198 y ss. ; Cea (1993 y 2001); Celotto (2006).

24 De Stefano (2005), p. 1.

25 Véase entre otros, Bordali (2003), p. 285; CEA (2005), p. 67; Colombo (2005), p. 585; ZúÑIGA y VEGA (2006), p. 146 ss.; Ríos (2005), p. 633 ss.; NogueIRA (2005), p. 593; Gómez (2005), p. 651 ss.; GÓMEZ (2013), p. 17 ss. 
los poderes públicos. Luego agrega (...) poco importa que este o aquel Tribunal Constitucional se denomine formalmente Consejo, Tribunal o, incluso Tribunal supremo constitucional, siempre que responda a la definición que acaba de esbozarse"26.

Este será el concepto que utilizaremos en la presente investigación a objeto de descartar que el sistema de control constitucional chileno a posteriori implementado a partir de la reforma constitucional, Ley $\mathrm{N}^{\circ}$ 20.050 de 2005 , sea un sistema de control concentrado.

\subsection{Sistemas de control de constitucionalidad de la Ley a posteriori en Chile: Difuso - Concentrado}

Al hablar de sistemas de control constitucionalidad, la primera referencia es la que distingue entre sistemas difusos y concentrados. De acuerdo con el Diccionario de la Real Academia de la Lengua Española, concentrado significa internado en el centro de una cosa; muy atento o pendiente de una actividad o competición; sustancia a la que se le ha retirado parte del líquido para disminuir su volumen. Por su parte, difuso viene del latín diffússus, que significa ancho, dilatado; excesivamente dilatado, superabundante en palabras o vago, impreciso ${ }^{27}$.

Para el profesor Ruiz-Tagle Vial, estos conceptos constituyen una dicotomía, "(...) son equívocos porque por una parte tienen una connotación o significado de distribución espacial y, por la otra, se refieren a una actitud mental o a un uso del lenguaje o del pensamiento que en un caso tiene valor positivo y en el otro, negativo". Luego agrega que "no debemos olvidar este equívoco cuando analizamos cómo la literatura constitucional ha usado estos términos como un par de conceptos opuestos $(\ldots)^{\prime 28}$.

Es necesario tener presente que en la actualidad no es posible catalogar un sistema como difuso o concentrado sin matices, ya que se han ido adaptando los modelos originarios a cada realidad social y jurídica,

26 FAVOREU (1994), p. 13 y 14.

27 Diccionario de la Real Academia de la Lengua Española (2001).

28 Ruiz-TAgLE (1999), p. 83. 
recogiendo aspectos de uno y otro modelo, afectando con ello la pureza de los mismos.

El sistema difuso es originario de Estados Unidos de Norteamérica, a partir de la sentencia de la Suprema Corte Marbury versus Madison, de 1803, en tanto que el modelo concentrado se debe a Hans Kelsen, y se concreta en Austria en 1920 en la Constitución de ese país. Todos los demás sistemas de control judicial tanto europeos como latinoamericanos no son más que copias de los referidos modelos originarios norteamericano y austríaco. Incluso el modelo originario concentrado sólo se mantuvo hasta 1925. A partir de ese año se le introducen las primeras modificaciones al Tribunal Constitucional austríaco, implementando un control previo de las leyes y, más tarde, en 1929, se incorpora un mecanismo de control concreto. Se trata de la cuestión de inconstitucionalidad, que podía ser requerida por el Tribunal Supremo29. Hoy en día los modelos de control de constitucionalidad de la ley no se presentan puros.

Para determinar si nuestro actual sistema de control de constitucionalidad es concentrado o difuso me basaré en algunos criterios extraídos de la doctrina extranjera y nacional. Posteriormente analizaré el sistema vigente en nuestro país a doce años de la Ley de Reforma Constitucional $N^{\circ} 20.050$. Así se podrá determinar si nuestro sistema de control de constitucionalidad de la ley actualmente vigente, es concentrado o difuso, o es una variante de ambos sistemas. Ello es importante, ya que los efectos de las sentencias emitidas por el órgano a cargo de dicho control serán distintos si se trata de un sistema difuso, al estilo norteamericano, o concentrado, de tipo kelseniano ${ }^{30}$.

\subsubsection{Criterios para determinar el carácter concentrado o difuso de un sistema de control de constitucionalidad de la} ley

Para abordar esta materia resultan relevantes los criterios establecidos desde hace ya bastante tiempo por la dogmática constitucional, y

29 Cruz (1987), pp. 265-269.

30 Cappelleti (1979), p. 51. 
que suelen ser olvidados al momento de catalogar un sistema de control de constitucionalidad de la ley. Esa labor exige explicar los aspectos o elementos que los diversos autores han considerado para calificar un respectivo sistema como concentrado o difuso. Así, por ejemplo, Carl Scmitt, en 1931, haciendo referencia a las características originales del sistema de control constitucional de Weimar, entendía el término difuso para designar el concepto opuesto al de derecho de control concentrado en una sola instancia ${ }^{31}$. Le daba por tanto una connotación procesal, que atendía a la existencia o no de una determinada instancia o al carácter incidental de la misma, lo que era propio del sistema original de la Constitución de Weimar.

Posteriormente, Mauro Capelletti, en 1966, vuelve a hablar de controles concentrado y difuso como categoría de análisis dogmático, al comparar las características del sistema de control constitucional austríaco y del sistema norteamericano ${ }^{32}$.

Capelletti atiende primeramente a un criterio orgánico o subjetivo. Es decir, al órgano u órganos a los cuales se les entrega el poder de control. Un primer tipo, en el cual (...) el poder de control es difuso, pues se distribuye entre varios órganos judiciales ordinarios; y un segundo tipo, en el cual, por el contrario, ese poder de control es concentrado, en virtud de que se centraliza en un solo órgano judicial"33. También analiza la forma en que se plantea y resuelve la controversia constitucional, esto es, el control difuso se ejerce por vía incidental, en tanto que el control concentrado se realiza por vía principal.

"[E]l control de las leyes que bajo el aspecto subjetivo posee, como se ha expresado con amplitud, las características de un control judicial difuso, desde un punto de vista formal adquiere la naturaleza de un control que se ejercita en vía incidental. El sistema austríaco, por el contrario, además del carácter concentrado que se ha mencionado con anterioridad, tiene además la naturaleza de un control que se ejercita por la vía

31 SCHMITT (1983), p. 52.

32 Capelletti (1966), pp. 35 y ss.

33 Ibid, p. 35. 
principal"34.

Capelletti también atiende a las características de los órganos que resuelven el juicio constitucional, distinguiendo entre ordinarios y especiales, así como a los efectos declarativos, constitutivos, retroactivos, generales y particulares de sus resoluciones ${ }^{35}$.

En los sistemas de control difuso quienes ejercen control son los órganos judiciales ordinarios. Se trataría de un control meramente declarativo. A su vez, en los sistemas de control concentrado quienes se pronuncian son órganos judiciales especiales. Se trata, entonces, de un control constitutivo de invalide $z^{36}$.

En cuanto a la eficacia o efecto de las sentencias, en un sistema de control difuso la eficacia de la decisión tendría un efecto meramente declarativo. Por ende, la sentencia de inconstitucionalidad opera ex tunc, es decir, retroactivamente, con efecto inter pares. Se declara una nulidad preexistente ${ }^{37}$. En cambio en un sistema de control concentrado se genera la invalidez y la consiguiente ineficacia de las leyes contrarias a la Constitución. La sentencia de inconstitucionalidad opera ex nunc, pro futro, excluyéndose la retroactividad, con efecto erga omnes.

Por su parte, Caamaño Domínguez explica las diferencias entre un sistema difuso y uno concentrado, a través de criterios orgánicos e institucionales, centrado en las funciones del ente que decide la controver-

34 Ibid, p. 53.

35 "Desde el punto de vista de los efectos de la decisión judicial, ya sea que provenga de los órganos judiciales ordinarios, como en los sistemas en los cuales el control tiene el carácter difuso, o por el contrario, cuando sea pronunciada por órganos judiciales especiales, como los tribunales constitucionales europeos (...) puede afirmarse, que mientras el sistema estadounidense de control judicial de la constitucionalidad de las leyes tiene el carácter de control meramente declarativo, a la inversa, el austríaco asume la naturaleza de un control constitutivo de la invalidez y de la consiguiente ineficacia de las leyes contrarias a la Constitución y de aquí se concluye con plena coherencia que, mientras en el primer sistema la eficacia (meramente declarativa) opera ex tunc, o sea, retroactivamente -se trata, en efecto, repito, de la simple declaración de una nulidad preexistente- en el sistema austríaco, por el contrario, la eficacia (constitutiva, es decir, de anulación) de la sentencia de inconstitucionalidad obra ex nunc y por lo tanto, pro futuro, excluyéndose una retroactividad de la eficacia de anulación. Ibid, p. 67.

36 En Chile, en virtud del artículo $7^{\circ}$ de la CPRCh, ocurre lo mismo. Toda norma contraria a la Constitución es inválida.

37 Capelletti (1966), pp. 35 y ss. 
sia constitucional. Al respecto, señala: "[L]ógicamente, estas diferencias orgánico-institucionales no son ajenas a la mayor o menor influencia de los dos grandes modelos de jurisdicción constitucional (el norteamericano de la judicial review y el austríaco o de control "concentrado") sobre cada uno de los sistemas nacionales objeto de examen. Sin embargo, y a pesar de las apuntadas diferencias, es posible establecer, desde una óptica funcional, un común denominador que otorga una sustancial identidad material a los referidos Tribunales y Salas de lo constitucional, a saber: el control constitucional de las normas y actos con valor de ley, así como la competencia para la resolución de conflictos entre órganos del Estado o de carácter territorial y para conocer de los remedios en cada país, para la protección y tutela de los Derechos Fundamentales de los ciudadanos"38.

A su vez, Cruz Villalón parte de un criterio muy similar al de Capelleti en relación a la vía por la que el órgano conoce la controversia constitucional, y a la idea de concentración propuesta por Schmitt. Atiende además al carácter reglado o no de dicho procedimiento. Así, sostiene que en los sistemas de control difuso las cuestiones de constitucionalidad se resuelven por vía incidental, remitiéndose a la idea de judicial reviem propia del sistema norteamericano. Este sistema no necesita ni suele estar escrito en parte alguna, ni en la Constitución ni en las leyes, ya que todo deriva del principio de primacía de la Constitución. En cambio, en el sistema europeo "(...) sólo el Tribunal Constitucional puede extraer las consecuencias jurídicas inherentes a una apreciación de inconstitucionalidad. El Tribunal Constitucional no sólo monopoliza el rechazo, sino que monopoliza la competencia para conocer en un proceso autónomo de constitucionalidad"39.

Desde otro punto de vista, Pereira Menaut sostiene que los términos difuso o concentrado pueden tener significados diversos. Así, se puede emplear el concepto concentrado si una institución se encuentra en un solo edificio y todos sus recursos materiales y humanos se encuentran en

38 CaAmaño (1998), p.4.

39 CRUZ (1987), p. 31 
un mismo lugar. Entonces diremos que hay concentración, y si se atiende a las funciones habría dispersión si existen en el sistema más órganos que ejercen la misma función de control, esto es, sería un sistema difuso. Por el contrario, si las funciones encomendadas son exclusivas y excluyentes se trataría de un sistema concentrado. Por tanto, en los sistemas de control de constitucionalidad de la ley habría que determinar cuáles son las funciones propias que ejerce el órgano encargado de efectuar el control. En otras palabras, el profesor español atiende a un criterio orgánico funcional para calificar el sistema de control constitucional ${ }^{40}$.

Así, por ejemplo, si aplicamos el criterio orgánico funcional para determinar cuál es el sistema de control de constitucionalidad en Chile, pareciera que éste no es puramente concentrado ni puramente difuso, ya que existen diversos tipos de control: control administrativo; control jurisdiccional por tribunales ordinarios; control jurisdiccional especializado TCCh. También acá ubicamos a los tribunales ordinarios en general, en especial a través de la acción de nulidad de derecho público, y finalmente un control por parte de la jurisdicción especial constitucional a cargo del Tribunal Constitucional. Dentro de este último cabe distinguir un control a priori y uno a posteriori. Además, no sólo se controla la ley, sino también otras fuentes normativas.

Por lo tanto, históricamente en nuestro sistema se han mezclado elementos tanto del sistema difuso norteamericano como del sistema europeo concentrado. Estas particularidades y características de nuestro sistema lo hace un modelo único. Como lo sostiene Brewer Carias cuando señala que "[E]n América Latina (...) debe destacarse el caso Chile donde el sistema concentrado de control de la constitucionalidad está conferido en forma exclusiva a dos órganos (...) separados: la Corte Suprema de Justicia, a través de una vía incidental, y el Tribunal Constitucional, a través de una acción directa ${ }^{41}$. Sin perjuicio de lo anterior, a efectos de esta investigación interesa en concreto el sistema de control de constitu-

40 Pereira (1999), pp. 221 y ss.

41 BREWER (1997), p. 123. Cabe hacer presente que este trabajo es anterior a la Reforma Constitucional de la Ley $\mathrm{N}^{\circ} 20.050$ de agosto de 2005. 
cionalidad de la ley.

Así las cosas, y siguiendo el criterio orgánico y funcional propuesto por el profesor Pereira Menaut, en el control de constitucionalidad de la ley que efectúa el TCCh habría que distinguir entre el control preventivo y el control a posteriori. Se podría decir que el control preventivo o a priori que realiza conforme al artículo $93 \mathrm{~N}^{\circ} 1$ de la CPRCh sería un control concentrado. En nuestro sistema no hay otro órgano que efectúe el control preventivo respecto de la ley, o más bien de los proyectos de ley, sin perjuicio de que existe este tipo de control para otros actos normativos.

Ahora bien, el control a posteriori presenta complejidades que hacen más difícil calificarlo en uno u otro sentido, dado que son diversos los actos normativos sujetos a control. Ello conduce a determinar en cada tipo de norma la clase de control que se aplica. No obstante, el control de constitucionalidad de la ley del artículo $93 \mathrm{~N}^{\circ} 6$ y 7 de la CPRCh tendría más bien un carácter marcadamente difuso, por las razones que explicitaré más adelante.

\subsubsection{Sistema de control de constitucionalidad de la ley en la Constitución de 1980 antes de la entrada en vigencia de la Reforma Constitucional de la Ley № 20.050 de 26 de agosto de 2005.}

Antes de la reforma de 2005 la doctrina se dividía en dos claras posiciones. Un primer grupo tenía como elemento común de su análisis las innovaciones introducidas por la Constitución de 1980 al sistema de control constitucional. Entre otros, formaban parte de dicho grupo José Luis Cea Egaña y Lautaro Ríos Álvarez. Un segundo realizaba un análisis descriptivo comparativo del sistema chileno con los modelos de control difuso y concentrado. En términos generales se concluía en este grupo que el sistema era difuso, para otros en cambio era concentrado, dentro del cual se hablaba de un sistema concentrado con judicatura dual, concentrado impropio, sistema híbrido y sistema doblemente concentrado o mixto. Suscribían esta posición, entre otros, Teodoro Ribera, Carlos Peña, Francisco Zúñiga Urbina, Francisco Vega, Kamel Cazor Aliste, Humberto Nogueira Alcalá y Gastón Gómez Bernales. 
Cea Egaña, en su obra Tratado de la Constitución de 1980, sin entrar a calificar el sistema instituido por la Constitución de 1980 como difuso o concentrado se limita a realizar una descripción comparativa entre el régimen de la inaplicabilidad bajo la Carta de 1925 y la nueva inaplicabilidad del artículo 80. Así señala que “(...) la declaración de inaplicabilidad de un precepto legal por la Corte Suprema no sólo se mantiene para defender la Constitución, sino que ahora, y además en forma explícita, se reconoce a dicho Tribunal la facultad de declarar de oficio que un precepto de esa índole es contrario en la forma o en el fondo a la Ley Fundamental, y no solamente en el caso de un juicio como ocurría en la Constitución anterior, sino que tratándose de cualquier gestión judicial"42.

Para Ríos Álvarez "[N]o obstante la especialidad del Tribunal Constitucional y su carácter supremo, autónomo e independiente, a la usanza europea, el sistema chileno reserva a éste sólo el control abstracto y preventivo de la constitucionalidad de las leyes; y -manteniendo una tradición histórica que se remonta a la Carta de 1925 y que le vincula al modelo norteamericano- le hace compartir con la Corte Suprema dicho control, entregando a ésta su fase represiva, es decir, la fiscalización posterior a la entrada en vigencia de la ley"43.

Ribera Neumann, contradiciendo en parte lo señalado por Cea Egaña, sostiene que "(...) surge en forma paulatina como contrapeso del aumento de las atribuciones del Presidente de la República y para hacer frente a la pasividad de los tribunales ordinarios de justicia en la defensa de la Constitución. Así se explica que, junto al sistema norteamericano modificado, que prevé una jurisdicción constitucional difusa -radicada en Chile en las Cortes de Apelaciones y en la Corte Suprema- coexista el sistema alemán-austríaco personificado en el Tribunal Constitucional. En términos generales puede indicarse, además, que la estructura de control constitucional se extiende también, entre otros órganos, a la Contraloría General de la República y al tribunal Calificador de Elecciones, lo que denota la inexistencia de una concepción global del legislador al

42 CeA (1988), p. 47.

43 Rios (2002), pp. 389 y ss. 
respecto" 44 .

Por su parte, Carlos Peña, en una posición contraria a la del profesor Ribera Neumann, ha señalado que el sistema de justicia constitucional chileno se caracteriza por la no existencia de una jurisdicción especializada en materia contenciosa administrativa, las que formarían parte de la jurisdicción ordinaria de competencia de los tribunales ordinarios, con un poder judicial que ejerce una justicia constitucional altamente difusa ${ }^{45}$.

Zúñiga y Vega señalaban que la Constitución de 1980 consagraba un sistema de control constitucional concentrado de judicatura dual, esto es, compartido entre el Tribunal Constitucional y la Corte Suprema. El primero, encargado del control preventivo de la constitucionalidad, en tanto que la segunda lo ejercía con carácter represivo ${ }^{46}$.

Para Cazor Aliste la Constitución contemplaba “(...) un modelo concentrado impropio, en virtud del sistema de jurisdicción compartida vigente en Chile"47, mientras que Gómez Bernales sostenía que el sistema de control constitucional era mixto o doblemente concentrado. "En el caso de Chile, como ya hemos sugerido, debemos indicar que el control constitucional se realiza concentradamente por dos vías y momentos diversos. El Tribunal Constitucional concentra la revisión abstracta-preceptiva o meramente facultativa de proyectos de preceptos legales, resolviendo, además, una serie de cuestiones relativas a decretos provenientes de la potestad ejecutiva. Coexiste con ello (y ésta es la segunda forma de concentración) la función de la Corte Suprema, una labor concentrada de judicial review, pues sólo ella puede declarar inaplicable un precepto legal vigente, con efecto inter pares, sin sujeción al staredecisis y para un caso concreto $^{48}$. Compuesto por el Tribunal Constitucional y la Corte Suprema. Así el sistema “(...) [P]resenta evidentes duplicidades y contradicciones en el parámetro de control que utilizan ambos órganos que componen el sistema, lo que afecta la coherencia de la Carta. La ausencia de una

44 RIBERA (1989), pp. 196-197.

45 PEÑA (1996), pp. 152-153.

46 ZÚÑIGA (2006), p.145.

47 CAZOR (2001), p. 96.

48 Gómez (1996), p. 14. 
jurisdicción constitucional concentrada se advierte en la técnica prevista por la Constitución para desbloquear los conflictos entre órganos constitucionales -excluidos, en general, los entre órganos colegisladores-. La solución prevista en el sistema es entregar a diversos órganos la resolución de estos conflictos, algunos de los cuales ni siquiera actúan ni fallan jurisdiccionalmente. Los conflictos que se producen entre la Corte Suprema y las autoridades políticas del Estado deben ser resueltos por el Senado, y aquellos suscitados entre autoridades y los jueces inferiores le corresponde resolverlos a la Corte Suprema ${ }^{49}$.

Nogueira Alcalá expresaba que "[E]n Chile existe un control de constitucionalidad que se desarrolla por dos instancias jurisdiccionales: el Tribunal Constitucional y la Corte Suprema, produciéndose un modelo híbrido que no responde a los lineamientos del modelo germano-austríaco europeo ni al modelo americano ${ }^{50}$.

Por su parte, Martínez Estay, Ríos Álvarez y Fernández González pensaban que el sistema de control era difuso.

Para Martínez Estay el modelo chileno era un tanto extraño, dada la convivencia de dos sistemas de control de constitucionalidad, a partir de la reforma constitucional introducida en 1970 a la Constitución de 1925. El control efectuado por la Corte Suprema a través de la inaplicabilidad por inconstitucionalidad hacía que el modelo se asemejara al del judicial review, "en cuanto supone la existencia de un caso concreto en el que se ejerce. Pero se diferencia de éste en cuanto se trata de un control concentrado en un solo órgano jurisdiccional" ${ }^{21}$.

Para Ríos Álvarez el control a posteriori que realizaba la Corte Suprema a través de la inaplicabilidad por inconstitucionalidad lo acercaba al modelo norteamericano ${ }^{52}$. Fernández González, atendiendo a la fuerza normativa de la Constitución, sostenía que cualquier juez estaba habilitado para dejar de aplicar aquellos preceptos legales que incidiendo en

49 Gómez (1997), pp. 125 y 127.

50 Nogueria (1995), p. 116.

51 Martínez (2003), pp. 715 y ss.

52 Rios (2002), p. 389 y ss. 
el caso concreto, sean contrarios a la Constitución ${ }^{53}$. "(...) si los jueces dan valor a una norma contraria a la Constitución es indubitado que están obrando fuera de su competencia, pues el arco de atribuciones que les confieren la Carta Fundamental y las leyes no les permite aplicar disposiciones contrarias a aquéllas, sino que -antes y al contrario- les ha ordenado dar aplicación a la Constitución, preteriendo las disposiciones legales o infralegales que la vulneran. De esta forma cumplen, entonces, lo dispuesto en el artículo $7^{\circ}$ incisos $1^{\circ}$ y $2^{\circ}$ de la Constitución... Por ende, cualquier tribunal puede $-\mathrm{y}$, repito, debe- dejar de considerar, para su pronunciamiento el precepto legal que, incidiendo en él, sea, sin embargo, contrario a la Constitución. De otra forma, la vinculación directa preconizada por el Poder Constituyente operaría en todos los casos, y respecto de todos los entes públicos y privados, con excepción de los jueces $(\ldots)^{\prime \prime 54}$.

\section{Control de constitucionalidad de la Ley a partir de la Reforma Constitucional Ley No 20.050}

La doctrina nacional mayoritaria, tanto antes como después de la reforma constitucional de 2005, califica el sistema de control constitucional de la ley como un sistema concentrado, salvo una posición minoritaria, que centrado en la inaplicabilidad lo concibe como un sistema difuso. Pero en el ámbito nacional, a diferencia de la doctrina extranjera citada, ninguno de los autores señala expresamente cuáles son los criterios, aspectos o características del sistema que utilizan para encuadrarlo dentro de la categoría de concentrado o difuso. A partir de la reforma constitucional de la Ley 20.050 , la gran mayoría de la doctrina nacional sostiene que hoy existe un control de constitucionalidad de carácter concentrado a cargo del Tribunal Constitucional, a través de la acción de inaplicabilidad y la cuestión de inconstitucionalidad (96 Ns 6 y 7).

53 FERNÁNDEZ (2001), pp. 97 y 98.

54 FERNÁNDEZ (2005), pp. 101 y ss. 


\subsection{Control de constitucionalidad concentrado}

Entre quienes sostienen esta posición pueden destacarse, por ejemplo, Cea Egaña, para quien "[l]ncumbe al Tribunal Constitucional, sobre todo después del control de supremacía más concentrado que contempla la reforma constitucional de 2005 (...) servir el rol de defensor supremo y garante máximo de la Carta Fundamental"55.

Por su parte, Colombo Campbell sostiene que en virtud de esta reforma se estableció un sistema de control concentrado y compartido. “(...) existe un control concentrado y compartido, y en tal evento tienen facultades de dictar estas resoluciones con diversos efectos el Tribunal Constitucional, los Tribunales Electorales, la Corte Suprema y las Cortes de Apelaciones" "56. Asimismo, Zúñiga Urbina y Vega entienden que se trataría de un control concentrado. El Tribunal Constitucional asume en plenitud la competencia de control concreto y control abstracto de normas, dejando de compartir el control de constitucionalidad con la Corte Suprema. "(...) Dado que en Chile el sistema de control de constitucionalidad imperante desde 1925, que pasa a ser dual en 1970, es de tipo concentrado y no difuso, el Juez nuca tuvo, ni actualmente tiene, la competencia para pronunciarse sobre la constitucionalidad de una norma legal, sino que -si el mérito del proceso lo exige- debe aplicarla lisa y llanamente. Pero, a menos que la inaplicabilidad fuese declarada por la Corte Suprema, de oficio o a solicitud de alguna de las partes, el juez no tenía más posibilidad que aplicar la norma legal al asunto que estaba conociendo. Después de la reforma constitucional, si la aplicación del precepto legal genera dudas en cuanto a su constitucionalidad, encontrándose pendiente el asunto que debe resolver, el propio Juez puede promover la acción de inaplicabilidad, de oficio"57.

En el mismo sentido, Ríos Álvarez, variando su criterio mantenido durante el período anterior, señala que el Tribunal Constitucional queda constituido como el supremo intérprete y custodio de la supremacía de la

55 CEA (2005), pp. 67-72.

56 Colombo (2005), p. 585.

57 ZÚNIIGA Y VEGA (2006), pp. 146, 148 y 150. 
Constitución. Más adelante concluye “(...) [H]emos avanzado desde un régimen incoherente, por hallarse compartido y segmentado entre dos órganos jurisdiccionales distintos e independientes entre sí, a uno concentrado en un solo Tribunal Supremo, independiente y especializado que asume en plenitud esta delicada función"58. "La reforma, al radicar esta acción en la competencia del T.C., termina con esta dualidad perturbadora de órganos y de sistemas. Concluye en Chile el control concentrado, pero compartido, entre dos tribunales de naturaleza diferente; y concluye la dispersión entre el control preventivo y el control correctivo o remedial de preceptos legales. Pero, principalmente, se pone fin a dos interpretaciones contrapuestas de la Constitución, que llegaron a generar incerteza e inseguridad jurídica"59

A su vez, Nogueira Alcalá sostiene que "[L]a importante reforma al sistema de control constitucional de normas jurídicas, el cual concentra dicho control en el Tribunal Constitucional, constituye un cambio de modelo de jurisdicción constitucional, el cual tiene importantes consecuencias en el sistema de defensa del orden constitucional"60.

Por su parte, Gómez Bernales destaca que "[L]a reforma modifica sustancialmente la jurisdicción constitucional. No es una reforma meramente formal. Se crea -por primera vez, cabría agregar- una genuina y concentrada jurisdicción constitucional atribuyendo al Tribunal Constitucional -desde ahora- el monopolio de la inaplicación e invalidación de leyes (en sentido genérico) en el ordenamiento jurídico chileno. Se trata de una reforma profunda que apunta a perfeccionar el carácter normativo de la Constitución, y que pone fin a la jurisdicción constitucional mixta (doble) que se instaló durante la vigencia de la Constitución de 1925"61.

Por último, el actual ministro del TCCh, Hernández Emparanza, ha señalado que "No cabe duda. La última palabra en materia de interpretación constitucional la dice el Tribunal Constitucional. La reforma de 2005

58 Rios (2005), pp. 633, 639 y 649.

59 lbíd., pp 639 y 649.

60 NogueIRA (2005), p. 593.

61 Gómez (2005), pp. 651-652. Gómez (2013), p. 17 ss. 
puso fin al debate que se había planteado en la doctrina constitucional en el sentido de si el artículo $6^{\circ}$ de la Constitución Política habilitaba una interpretación en el sentido que nuestro constituyente habría optado por un modelo de justicia constitucional difuso, al estilo norteamericano. Ese planteamiento es difícilmente sostenible hoy día, entregado como está el control de constitucionalidad de preceptos legales al TC, en desmedro de la Corte Suprema"62.

\subsection{Sistema de control constitucional difuso}

No obstante lo anterior, para un sector minoritario de la doctrina nacional el sistema de control constitucional actualmente vigente sería difuso. Así lo han sostenido Martínez Estay, Aldunate Lizana y Núñez Poblete.

Para Martínez Estay “(...) el artículo $6^{\circ}$ de la Constitución supone hasta hoy para el juez el deber de preferir la Constitución a una norma legal contraria a ella. Por tal razón el juez está obligado a aplicar la Constitución, e inaplicar los preceptos legales inconstitucionales, incluso en el evento que las partes o interesados en la gestión no interpusieran el recurso". Más adelante agrega "(...) el nuevo artículo 93 esclarece definitivamente el problema. Como ya se dijo, esta norma entrega una facultad al juez para plantear sus dudas de constitucionalidad ante el Tribunal Constitucional. Pero se trata de una facultad y no de un deber. Por tanto, si hay duda el juez puede o no plantearla al Tribunal Constitucional, y desde luego si no la tiene y entiende que un precepto legal es inconstitucional, parece obvio que simplemente deberá inaplicarlo, porque de lo contrario estaría infringiendo la Constitución" 63 .

Por su parte, Aldunate Lizana, refiriéndose al juez de la instancia y la aplicación de leyes inconstitucionales, ha señalado que "(...) no puede entenderse que el recurso de inaplicabilidad prive al órgano jurisdiccional de una facultad ajena a éste (o a la jurisdicción como atributo, habría que decir con mayor propiedad), cual es pronunciarse sobre la antinomia cuando ella se produce. Menos aún puede estimarse que la consagra- 
ción del recurso de inaplicabilidad dispense al juez de la instancia de su deber de cumplir cabalmente con el artículo $6^{\circ}$ y dar primacía a la Constitución por sobre las normas que la contravengan. Si al hacerlo, el juez aplica mal el derecho, queda abierto el camino de recursos ordinarios o extraordinarios, incluyendo casación en el fondo cuando sea procedente, para examinar la corrección de su criterio jurídico al resolver la antinomia entre Constitución y ley" 64 .

Con algunos matices, que de uno u otro modo se entremezclan con los argumentos anteriores, a la misma conclusión ha llegado Núñez Poblete. Al analizar las vías que utiliza el TCCh a objeto de determinar los efectos que un precepto legal puede producir en una gestión judicial, señala que "(...) dos de esas vías -la intervención sobre el proceso de interpretación conforme y sobre el proceso de identificación del campo de aplicación de la ley-corresponden a la tarea ordinaria de cualquier juez, y por lo tanto difícilmente pueden calificarse de atributos monopólicos de la jurisdicción constitucional". Más adelante agrega (...) en el campo de la inaplicabilidad existen al menos dos aéreas vastas y relevantes respecto de las cuales el Tribunal no renuncia, pero de las cuales no puede pretender exclusividad: el control de la interpretación y de la definición del campo de aplicación de la ley. Esas áreas surgen, entonces, como campos necesariamente yuxtapuestos de la inaplicabilidad y de la jurisdicción ordinaria" 65 .

Para estos efectos, es importante tener presente la distinción entre desaplicar e inaplicar un precepto legal ${ }^{66}$. En esta materia seguiremos al profesor Núñez Poblete.

Por desaplicación vamos a entender, "la omisión fundada y legitima del juez de resolver conforme a los criterios indicados en una norma dada. Es fundada porque ni es obra del arbitrio ni de la ignorancia del juez, y es legítima porque a través de ella el juez se mantiene dentro de la juridicidad. (...) de la no aplicación de la norma solo se sigue un resultado di-

64 Aldunate (2008), pp. 203 y 204. Cordero y Aldunate (2013), pp. 89, 90 y 91.

65 NúNÉEZ (2012), pp. 207-208.

66 Sobre el particular véase NúÑEZ (2012), p. 27 ss. 
verso en la decisión del asunto, manteniéndose inalterada la vigencia y la validez de la regla desaplicada" 67 . Dicho atributo correspondería a todos los jueces como parte fundamental de las atribuciones jurisdiccionales. Luego entonces, el proceso de interpretación conforme y la identificación en cuanto a la aplicación de la ley, le corresponde a cualquier juez de la República.

En tanto, la inaplicabilidad en palabras del propio Tribunal Constitucional consiste en "determinar si la aplicación de un precepto en la gestión especifica resulta contraria a la Constitución"68. Esto es, la inaplicabilidad se centra en los efectos de la aplicación de un precepto legal en la gestión pendiente. En el mismo sentido, el profesor Ríos Carmona ha señalado que "(...) en este instituto procesal -además del juez y de las partes- comparecen tres elementos de cotejo necesarios para su decisión, a saber: la norma constitucional, el precepto legal cuya inaplicación se solicita y -lo más específicamente decisivo- el examen particular acerca de si, en este caso, la aplicación del precepto cuestionado pudiera generar efectos opuestos a la finalidad implícita de aquella (...)". Luego agrega “(...) puede advertirse que hay preceptos legales que pueden estar en perfecta consonancia con la carta fundamental y, no obstante ello, ser inaplicables a un caso particular, precisamente porque en la particularidad de ese caso, la aplicación de una norma legal objetada es contraria a los efectos previstos por la norma constitucional"69.

Así el Tribunal Constitucional ejerciendo sus facultades jurisdiccionales por vía de inaplicabilidad se acerca mucho a las funciones jurisdiccionales que realiza la judicatura ordinaria dando origen a competencias concurrentes, haciendo el sistema más difuso que concentrado. A objeto de evitar esta concurrencia de competencias, el Tribunal Constitucional de manera casuística a identificado ciertas circunstancias que evitan que se apropie de competencias propias del juez del fondo, por ejemplo, el

67 NúÑEZ (2012), p. 194.

68 Sentencia Rol N ${ }^{\circ} 480$, considerando $27^{\circ}$ de 27 de junio de 2006.

69 Rios (2009), pp. 77 y 78 . Esta tesis es recogida por el Tribunal Constitucional en su Sentencia Rol N 478 INA, de 11 de abril de 2006, considerando $15^{\circ}$. 
pronunciamiento sobre la de un precepto legal de las leyes en el tiempo; los juicios sobre legalidad; el juicio sobre la existencia de hechos sustanciales, pertinentes y controvertidos; calificación jurídico-penal de los hechos; identificación de los preceptos conforme a los cuales debe ser resuelta una determinada gestión ${ }^{70}$.

Así las cosas, el modelo actual solo exige que los resultados de la aplicación de una norma sean contrarios a la Constitución, "por lo que de juicios sobre normas la inaplicabilidad pasa a transformarse en juicio sobre aplicación de normas"71. Así a través del juicio constitucional de inaplicabilidad, la judicatura constitucional se acerca en muchos casos a la facultades o atribuciones que posee la judicatura ordinaria, volviendo el control de la ley vigente en un sistema que no es ni difuso ni concentrado, sino más bien confuso, un sistema hibrido. Cuestión que explicaremos y profundizaremos en el apartado siguiente.

\section{Sistema de control de constitucionalidad de la ley híbrido: Difuso en la base y concentrado en la cima. Esencialmente concreto}

En mi opinión, la Ley de Reforma Constitucional № 20.050 estableció un sistema de control de constitucionalidad de la ley que no es ni concentrado ni difuso, sino más bien confuso, de naturaleza híbrida. Nuestro sistema de control constitucional es difuso en la base y concentrado en la cima, con un carácter esencialmente concreto, y que a diferencia de la legislación comparada como España, Alemania, Francia, Portugal, entre otros, nuestro Tribunal Constitucional no cierra el sistema. En otras palabras, el TCCh no tendría la última palabra en materia de interpretación y aplicación de la Ley Suprema72.

Lo antes señalado obedece principalmente al hecho de que el diseño

70 Véase entre otras, Sentencia del Tribunal Constitucional Roles Nº: 503 INA, de 15 de mayo de 2006; 480 INA, de 13 de abril de abril de 2006; 790 INA, de 25 de mayo de 2007; 796 INA, de 06 de junio de 2007; 806 INA, de 27 de junio de 2007; 549 INA, de 24 de julio de 2006, 806 INA, de 27 de junio de 2007.

71 NúÑEZ (2012), p. 222.

72 En sentido contrario, entre otros véase NogueIRA (2010), p. 101; CEA (2005), pp. 68 y 69. 
de inaplicabilidad genera una permanente convivencia entre la judicatura ordinaria y la judicatura Constitucional en cuanto importa interpretación y aplicación de preceptos legales respecto de una gestión pendiente, que es propia de los jueces de fondo, unida a las atribuciones que en materia de protección de derechos fundamentales poseen los tribunales ordinarios. Ello puede traducirse en conflictos entre el Tribunal Constitucional y la Corte Suprema, al tratar de imponer su interpretación sobre el sentido y alcance de las normas constitucionales, y tal como está diseñado el sistema pareciera que corre con ventajas la Corte Suprema. Dado el diseño de nuestra inaplicabilidad, lo convertirían en un sistema de control único. Sin perjuicio de estimar que posee un problema de diseño que no será tratado acá.

Las razones que me llevaron a plantear esta posición surgen de una serie de características propias de nuestro sistema; a saber, los órganos que intervienen en el control y sus características, la vía en virtud de la cual conocen de la materia constitucional, la eficacia y efecto de su decisión. Estos criterios pueden reducirse a un criterio orgánico, funcional y sustancial. En otras palabras, he seguido los parámetros establecidos por autores como Mauro Capelleti, Karl Loeweistein, Francisco Caamaño Domínguez y Antonio Carlos Pereira Menaut.

Es la combinación de los elementos, aspectos y características del sistema de control constitucional antes reseñados los que van a determinar el tipo de control vigente. Ello porque en general hoy los modelos no se presentan puros. Los modelos originales sólo funcionan dentro de la realidad en la que han sido creados, el difuso en Estados Unidos y el concentrado en Austria, este último con modificaciones respecto del concebido en la Constitución de 1920. Por su parte el sistema concentrado europeo ya no es una copia del sistema concentrado original, sino que incluye adaptaciones conforme a la realidad donde se aplica.

La consideración de uno de estos elementos en forma aislada nos puede llevar a conclusiones erróneas. Así por ejemplo, si se considera sólo el criterio orgánico, el sistema de control constitucional en Chile sería concentrado, ya que estaría radicado en el TCCh. A su vez, si se atiende al criterio funcional el sistema de control de constitucionalidad de 
la ley sería difuso. Ello porque la interpretación y aplicación de la CPRCh no es una función exclusiva y excluyente de la jurisdicción constitucional, también le corresponde a la judicatura ordinaria.

En efecto, en primera línea encontramos a los tribunales ordinarios, a los tribunales superiores de justicia, a los tribunales especiales. Ahora, si aplicamos el criterio orgánico funcional, el control preventivo que realiza el TCCh sería concentrado, dado que no hay otro órgano en nuestro sistema que realice un control preventivo de la ley. Por último, si se considera sólo la vía en virtud de la cual el órgano encargado del control conoce, el control de constitucionalidad de la ley vía inaplicabilidad sería difuso, ya que el TCCh conoce por vía incidental y no principal el requerimiento de inaplicabilidad.

Para corroborar la posición adoptada analizaré los aspectos, características y efectos del sistema de control de constitucionalidad de la ley vigente. Debe tenerse presente que nuestro estudio se centra sólo en el control de constitucionalidad de la ley a posteriori de los numerales 6 y 7 del artículo 93 la CPRCh, que es sólo a partir de su incorporación que podría sostenerse que el sistema chileno se ha transformado o ha avanzado hacia un modelo concentrado. Por lo tanto, los parámetros a considerar con miras a calificar el sistema de control sólo se predican de dicho control.

\subsection{Parámetros y características}

a) Orgánico o subjetivo. Atendiendo al órgano u órganos que participan en el control de constitucionalidad, tenemos en un primer momento al juez de la gestión pendiente, para quien conforme al artículo 93 es facultativo y no obligatorio plantear la duda de constitucionalidad. Planteada la cuestión le corresponderá al juez constitucional determinar si la interpretación que se propone produce o no efectos contrarios a la Ley Suprema. En otras palabras, en el proceso constitucional de inaplicabilidad participan tanto la judicatura ordinaria como la judicatura constitucional.

b) Vías o mecanismos para resolver la controversia constitucional. A este respecto, la inaplicabilidad surge en el curso de un proceso que 
debe estar pendiente, y puede ser planteada directamente tanto por las partes de dicha gestión como por el juez de la causa sub lite. Por lo tanto, se trata de un incidente respecto del caso del fondo. En otras palabras, no puede haber inaplicabilidad si no hay gestión previa. La inaplicabilidad no es una acción autónoma independiente o principal, es una cuestión accesoria que depende de la gestión principal. Por lo tanto, se plantea por vía incidental y no principal ante el TCCh.

c) Características de los órganos que resuelven el juicio de constitucionalidad. Acá se trata de determinar si el órgano o los órganos que intervienen en el contencioso constitucional son ordinarios o especiales. En nuestro caso participan del control órganos ordinarios y uno especial. Esto es, intervienen tribunales de justicia y el Tribunal Constitucional como órgano especial, autónomo e independiente del Poder Judicial.

d) Efectos de la decisión constitucional. En cuanto a los efectos de la sentencia que se adopte, hay que distinguir entre el control vía inaplicabilidad y el control vía inconstitucionalidad. El control de constitucionalidad a través de la inaplicabilidad es un control concreto meramente declarativo. La interpretación del precepto legal tenido por inconstitucional no se aplica al caso particular, pero se mantiene vigente en el ordenamiento jurídico, con eficacia inter partes. Es un efecto similar a lo que ocurre guardando las proporciones- con el sistema norteamericano. En éste, la norma cuestionada de constitucionalidad no se aplica al caso concreto, pero sigue vigente, manteniéndose en un statu quo, aunque en virtud del staredecisis emanado de la Suprema Corte norteamericana tendría eficacia erga omnes.

Por su parte, el control de constitucionalidad a través de la cuestión de inconstitucionalidad del número 7 del artículo 93 de la Constitución, es un control abstracto, como ocurre habitualmente en el derecho comparado. Pero el caso chileno presenta una peculiaridad, ya que requiere previamente la declaración de inaplicabilidad del precepto legal. En otras palabras, la inaplicabilidad es un requisito procesal de la inconstitucionalidad, lo que hace al nuestro único y especial. Por la misma razón, el carácter abstracto del control es sólo teórico. Y es que siendo la inaplicabilidad requisito de la inconstitucionalidad, resulta difícil que el juez constitucional 
se abstraiga del caso particular al momento de fallar.

Se genera la invalidez y consiguiente ineficacia de las normas declaradas inconstitucionales. En este sentido es un control de carácter constitutivo, con eficacia erga omnes, con efecto ex nunc, pro futuro, excluyéndose la retroactividad.

e) Otro aspecto no menor a considerar, y que apoya esta postura, es la redacción y diseño de la inaplicabilidad en el artículo $93 N^{\circ} 6$ de la Constitución, en aquella parte que reemplaza la expresión "precepto legal contrario a la Constitución" por "precepto legal cuya aplicación en cualquier gestión que se siga ante tribunal ordinario o especial, resulte contrario a la Constitución". Entonces, el problema no se centra en el simple cotejo entre un precepto legal y la Constitución, sino que en la interpretación del precepto legal y su aplicación en la gestión pendiente.

Por tanto, es el juez el primero que es llamado a realizar la interpretación del precepto legal confrontándolo con la Constitución, para luego determinar si su aplicación resulta o no contraria a ésta. De este ejercicio hermenéutico va a depender si se plantea o no la inaplicabilidad. Posteriormente, en un segundo momento, planteada que sea la inaplicabilidad, el mismo ejercicio que ya había realizado previamente el tribunal del fondo, lo realiza ahora el TCCh${ }^{73}$. Por tanto, en este punto conviven o se entremezclan ambas jurisdicciones, la ordinaria y la constitucional. En palabras de Zagrebelsky "hay que subrayar la relación entre interpretación y aplicación, que no es una conjunción ocasional sino un nexo de inescindibilidad: que en el Derecho no haya aplicación sin interpretación puede resultar claro, hasta banal; menos claro, pero por otra parte verdadero, es el inverso; que no hay interpretación sin aplicación. La esencia del Derecho está en este nexo, en el cual se manifiesta su valor práctico"74. Así las cosas, la inaplicabilidad resulta ser un sistema de control

73 Véase entre otras, Tribunal Constitucional, Rol N 480-2006-INA, de 13 de abril de 2006; Tribunal Constitucional, Rol N ${ }^{\circ}$ 546-2006-INA, de 21 de junio de 2006; Tribunal Constitucional, Rol N 1.065-2008-INA, de 24 de abril de 2008, Tribunal Constitucional, Rol N 1.234-2009-INA, de 22 de septiembre de 2008, Sentencia Tribunal Constitucional Rol No 1.281-2008-INA, de 05 de diciembre de 2008.

74 ZAGREBELSKY (2008), p. 161. 
difuso de la ley.

Analizados los aspectos, características y consideraciones en torno a los criterios relevantes para calificar el sistema de control de constitucionalidad de la ley en nuestro país, podemos concluir tal como lo habíamos anticipado, en Chile existe una mezcla de aspectos que responden tanto al sistema difuso como también a los sistemas concentrados. Se observa sí una preponderancia del sistema difuso de control vía acción y cuestión de inaplicabilidad, mecanismos que constituyen la regla general en materia de control, ya que la inconstitucionalidad implica la invalidez de la norma ya declarada inaplicable, y constituye un instrumento de última ratio. En este sentido, no todas las inaplicabilidades derivan necesariamente en inconstitucionalidades. El principal intérprete de la Norma Suprema deberá buscar aquella interpretación que más se adecue al mandato constitucional, y sólo en aquellos casos que no sea posible armonizar la interpretación de un precepto legal con el texto constitucional, deberá declarar su inconstitucionalidad.

Así las cosas, el rol principal en materia de control lo tiene la judicatura ordinaria y las partes de la gestión pendiente. Por una parte, el juez a quo debe suspender la aplicación de las normas contrarias a la Constitución, en virtud del mandato del artículo 6, velando de esa manera por la Supremacía constitucional conforme al artículo 7, ambos de la CPRCh. En otras palabras, cualquier juez de la República puede dejar de aplicar la ley de manera preventiva. “(...) Pero el juez, en la interpretación, dentro del marco de regulación previamente fijado por el tenor literal, decide entre diversas posibilidades interpretativas (Roxin, C.; Ob. cit.; págs.; 149 -150)"75. No por nada el instrumento para ello se llama "inaplicabilidad", planteando la duda al TCCh a fin de que éste resuelva en definitiva sobre la constitucionalidad. Pero el único que puede declarar la inconstitucionalidad con efecto erga omnes es el Tribunal Constitucional. En palabras de Favoreu, "no hay juez ordinario y juez constitucional, todos los jueces

75 Tribunal Constitucional Rol № 1281-2009, de fecha 14 de marzo de 2009, considerandos 21 y 22. 
aplican la justicia constitucional"76.

En otras palabras, y lo que es lo mismo, lo único que concentra en esta materia el TCCh a partir de la Reforma de 2005, es el poder de invalidación de las normas contrarias a la Constitución. Así cualquier juez de la República puede inaplicar la ley, pero no puede invalidarla. El único órgano que de manera exclusiva y excluyente se encuentra facultado para ello, es el TCCh. Pero sólo puede ejercer dicho poder respecto de preceptos normativos tenidos como inaplicables en un caso particular.

Todas estas características y particularidades hacen que el sistema sea en la práctica esencialmente concreto $^{77}$, resultando un sistema de control constitucional de la ley de naturaleza híbrida difuso en la base y concentrado en la cima esencialmente concreto. Se diferencia de otros modelos comparados -sean concentrados o difusos- por la no existencia de un mecanismo que le permita al TCCh cerrar el sistema, en el sentido de que no tiene totalmente la última palabra, como sucede en el caso español a través del amparo constitucional. En virtud de éste, el TCE puede modificar las sentencias de los tribunales ordinarios de justicia. Algo similar ocurre con el recurso de apelación ante el Tribunal Constitucional portugués, que genera el mismo efecto, o el amparo en el caso del Tribunal Constitucional Federal alemán.

\section{Conclusiones}

1. A partir de la Reforma Constitucional de 2005 el modelo de justicia constitucional tiene una naturaleza híbrida. Éste se caracteriza por ser difuso en la base y concentrado en la cima, esencialmente concreto pero

\footnotetext{
76 FAVOREU (1998-1999), p. 11.

77 En el mismo sentido Gugliano Herani, Renato señala que "Todo control de (in)constitucionalidad es realizado en concreto, de algo concreto, para producir efectos concretos. No siempre es difuso, pues puede ser concentrado, pero es siempre concreto. Cuando juzga la inconstitucionalidad legislativa, aunque en control concentrado, el juez resuelve un caso práctico, que envuelve hechos sociales e institucionales individuales y genéricos. Tal afirmación contraría el dogma de la no remisión fáctica construida por la figura kelseniana del legislador negativo. Incluso cuando la decisión de (in)constitucionalidad no es aplicada a un caso individual intersubjetivo (pretensiones individuales subjetivas resistidas), como ocurre en el control concentrado, el conflicto internormativo es, por sí solo, un problema concreto y no abstracto". Gugliano (2015), p. 19.
} 
que no está cerrado o a lo menos no lo cierra el Tribunal Constitucional. La combinación de los distintos factores, tales como las características del órgano que resuelve el conflicto constitucional, la vía o vías en virtud de la cual conoce o efectúa el control, el efecto de las decisiones, entre otros, nos permite determinar hacia dónde se inclina la balanza. Esto es, si posee más características de un sistema de control difuso o si es más cercano a uno concentrado.

2. Nuestro modelo de control de constitucionalidad de la ley a posteriori es único. Ello se manifiesta claramente dado el diseño que presenta la inaplicabilidad y la exigencia de constituir un requisito procesal sine qua non de la inconstitucionalidad. El diseño de inaplicabilidad genera una permanente convivencia entre la judicatura ordinaria y la judicatura Constitucional en cuanto importa interpretación y aplicación de preceptos legales respecto de una gestión pendiente, que es propia de los jueces de fondo, unida a las atribuciones que en materia de protección de derechos fundamentales poseen los tribunales ordinarios. Ello puede traducirse en conflictos entre el Tribunal Constitucional y la Corte Suprema, al tratar de imponer su interpretación sobre el sentido y alcance de las normas constitucionales, y tal como está diseñado el sistema pareciera que corre con ventajas la Corte Suprema.

3. En el caso chileno, la denominación justicia constitucional resulta ser una expresión más apropiada si se considera el término justicia como sinónimo de judicial. Pero además permite considerar el carácter axiológico que estos instrumentos pueden tener, lo que permitiría incluir algunos otros instrumentos $u$ organismos que también participan en la tarea de interpretación y aplicación de la Constitución (principalmente Tribunales Ordinarios y Especiales; Contraloría General de la República). Desde un punto de vista procesal una y otra jurisdicción conocen de manera exclusiva los procesos que les han sido atribuidos. Pero desde el punto de vista material, esto es, el ejercicio de la justicia constitucional, ambas jurisdicciones confluyen en su actividad. Sin embargo, hay que tener presente que en esta materia la jurisdicción constitucional es suprema, y tiene el monopolio de la invalidación de las leyes, resultando cuestionable el carácter de suprema. 
4. Ningún sistema de control de constitucionalidad de la ley es puro, dado que cada país le introduce modificaciones al modelo original. Estos sólo funcionan como tales en los países en que han sido creados, el difuso en Norteamérica y el concentrado en Austria, con la variante del modelo europeo actual. De ahí que nuestro modelo definitivamente no es concentrado, pero tampoco es difuso, es más bien confuso.

\section{Bibliografía}

Aldunate Lizana, Eduardo (2008): Derechos Fundamentales (Santiago de Chile, Editorial Legal Publishing).

Aragón ReYes, Manuel (1986): "La interpretación de la Constitución y el carácter objetivado del control jurisdiccional”, en Revista Española de Derecho Constitucional (AÑO 6, No 17). pp. 85-136.

Aragón Reyes, Manuel (2007): "Relaciones entre Tribunal Constitucional y Tribunal Supremo", en Revista Iberoamericana de Derecho Procesal Constitucional ( $\left.\mathrm{N}^{\circ} 8\right)$, pp. 31-39.

Bordalí Salamanca, Andrés (2003): "La Justicia Constitucional", en Revista de Derecho (Valdivia) (Volumen XIV). pp. 285-291.

Brewer Carias, Allan (1997): "La jurisdicción constitucional en América Latina”, en Domingo García Belaúnde-Francisco Fernández Segado, La jurisdicción constitucional en Iberoamérica, (Madrid, Dykinson S.L.) pp. 117-161.

CaAmaño Domínguez, Francisco (1998): “Informe General, Criterios, Condiciones y Procedimientos de Admisión a la Justicia Constitucional, desde la perspectiva de su racionalidad y funcionalidad", en Anuario Iberoamericano de Justicia Constitucional (Madrid, Centro de Estudios Políticos y Constitucionales). pp. 1-427.

Capelletti, Mauro (1960): "La justicia constitucional en Italia", en Revista de la Facultad de Derecho (Tomo X, Ns 37, 38, 39 y 40), pp. 267-306. CAPElletti, Mauro (1961): La jurisdicción constitucional de la libertad, con referencia a los ordenamientos alemán, suizo y austriaco, (traducc. Héctor Fix Zamudio, México, Editorial Imprenta Universitaria).

CAPELlettI, Mauro (1966): El control judicial de la constitucionalidad de las 
leyes en el Derecho Comparado (Universidad Autónoma de México, México).

Capellett, Mauro (1986): “¿Renegar de Montesquieu, la expansión y la legitimidad de la justicia constitucional?", en Revista Española de Derecho Constitucional (AÑO 6, No 17), pp. 9-46.

Cappelletti, Mauro (2007): "La justicia constitucional y Dimensiones de la justica en el mundo contemporáneo", en Revista Cuestiones Constitucionales, México, Porrúa-UNAM. Disponible en https://revistas.juridicas.unam.mx/index.php/cuestiones. [consultado el 31 de agosto 2018] CARTABIA, MARTA (2007): "El diálogo entre tribunales a la hora del activismo constitucional del Tribunal de Justicia", en Revista Española de Derecho Europeo, $\left(\mathrm{N}^{\circ} 22\right)$. pp. 1-28

Cazor Aliste, Kamel (2001): "La jurisdicción constitucional en Chile", en Revista de Derecho (Valdivia) (Volumen XII, N 1). pp. 91-106.

Cea Egaña, José Luis (1988): Tratado de la Constitución de 1980 (Santiago de Chile, Editorial Jurídica de Chile).

Cea Egaña, José Luis (1993): "Misión cautelar de la justicia constitucional", en Revista Chilena de Derecho (Tomo I, Volumen XX). pp. 395-408.

Cea Egaña, José Luis (2001): "La justicia Constitucional en las Facultades de derecho chilenas", en Revista de Derecho (Volumen XII, N 1). pp. 273-277.

Cea Egaña, José Luis (2001): "La justicia constitucional y el Tribunal de la Constitución en Chile", en Revista de Derecho (Concepción) (Volumen) XX. pp. 107-118

Cea Egaña, José Luis (2005): "El proyecto de reforma constitucional sobre los efectos de las sentencias del Tribunal Constitucional sobre la justicia ordinaria", en Revista Estudios Constitucionales (Año 3, № 1). pp. 67-72.

Celotto, Alfonso (2006): "Evolución de la justicia constitucional en Italia", en Revista de opinión jurídica Urbe et lus ( $\left.N^{\circ} 5\right)$, pp. 81-90.

Colombo Campbell, Juan (2005): "Tribunal Constitucional: Integración, competencia y sentencia", en Francisco Zúñiga Urbina (Coord.) en Reforma Constitucional (Santiago de Chile, Editorial LexisNexis). pp. 551-592. 
Cordero Quinzacara, Eduardo y Aldunate Lizana, Eduardo (2013): Estudios Sobre el Sistema de Fuentes en el Derecho Chileno (Santiago de Chile, Editorial Legal Publishing).

Corzo Sosa, Edgar (1993): "Relaciones entre el Tribunal Constitucional y el Poder Judicial en España”, en Revista Jurídica. Boletín Mexicano de Derecho Comparado ( $\left.\mathrm{N}^{\circ} 78\right)$. pp. 11-29.

Couso Salas, Javier y Coddou Macmanus, Alberto (2010): "La naturaleza jurídica de la acción de inaplicabilidad en la jurisprudencia del Tribunal Constitucional: Un Desafio Pendiente", en Revista Estudios Constitucionales (AÑO 8, $\mathrm{N}^{\circ}$ 2). pp. 389-430

Covian Andrade, Miguel (2013): Fundamentos teóricos del control de la constitucionalidad, Instituto de Investigaciones Legislativas del Senado de la República, pp. 91-112. Disponible en https://archivos.juridicas. unam.mx/www/bjv/libros/7/3180/9.pdf.

Cruz Villalón, Pedro: (1987): La formación del Sistema Europeo de control de constitucionalidad (1918-1939), en Anuario de Historia del Derecho Español (Madrid, España, Centro de Estudios Políticos y Constitucionales). pp. 585-587.

De Stefano, Juan Sebastían (2005): "El control de constitucionalidad", en Revista de opinión jurídica Urbe et lus (AÑO 1, № 7). pp. 152-172.

FAVOREU, Louis (1994): Los Tribunales Constitucionales. (Barcelona, Editorial Ariel S.A.).

FAVOREU, LouIS Joseph (1999): 1998-1999: “Justicia y jueces constitucionales”, en Revista de Derecho Público, Universidad de Chile, (Volumen 61). pp. 10-16.

Fernández González, Miguel Ángel (2001): "La fuerza Normativa de la Constitución", en Revista de Derecho Público, Universidad de Chile (Volumen 63, Tomo 1). pp. 77-102.

Fernández GonzÁlez, Miguel Ángel (2005): "Constitución y casación: ¿De la falta de aplicación al monopolio constitucional?", en Revista Estudios Constitucionales (AÑO 3, № 1). pp. 97-118.

FIX ZAmudio, HÉCtor (1982): "La Constitución y su defensa”, en Coloquio Internacional, Instituto de Investigaciones Jurídicas. Universidad Autónoma de México. 
García Pelayo, Manuel (1982): "Estado Legal y Estado Constitucional de Derecho", El Tribunal de Garantías de Debate. Consejo Latinoamericano de Derecho y Desarrollo. (Perú, Fundación Friedrich Naumann). Garrote Campillay, Emilio Alfonso (2012): "Cosa Constitucional Sui Generis y su efecto en las sentencias del Tribunal Constitucional en materia de Inaplicabilidad e Inconstitucionalidad", en Revista Estudios Constitucionales (Volumen 10, $\mathrm{N}^{\circ}$ 2). pp. 391-428

Garrote Campillay, Emillo Alfonso (2017): "Derecho Constitucional y Derecho ordinario una estrecha y permanente relación a partir de la Constitución: Un análisis de legislación comparada", en Revista Scientia luris, Londrina (Volumen 21, $\mathrm{N}^{\circ}$ 2). pp. 10-40.

Gómez BeRnales, Gastón (1996): "El control de constitucionalidad y el Tribunal Constitucional de 1980", en Estudios sobre jurisdicción constitucional, Cuadernos de Análisis Jurídico ( $\left.\mathrm{N}^{\circ} 31\right)$. (Santiago de Chile, Universidad Diego Portales, Carrera de Derecho).

Gómez Bernales, Gastón (1997): "La justicia constitucional en Chile", en Anuario Iberoamericano de Justicia Constitucional. pp. 121-156.

Gómez Bernales, Gastón (2005): "La Reforma Constitucional a la Jurisdicción Constitucional. El Nuevo Tribunal Constitucional Chileno", en Francisco Zúñiga Urbina (Coord.) Reforma Constitucional (Santiago de Chile, Editorial LexisNexis).pp. 651-684.

Gómez Bernales, Gastón (2013): Las sentencias del Tribunal Constitucional y sus efectos sobre la jurisdicción común (Santiago, Ediciones Universidad Diego Portales).

Gugliano Herani, Renato (2015): "La Prueba de la Inconstitucionalidad", en Revista Estudios Constitucionales (AÑO 13, No 1). pp.13-72.

HeRnÁndez Emparanza, Domingo (2012): "Acerca del rol del Tribunal Constitucional, su relación con Poder Judicial (sic), la interpretación constitucional y los derechos fundamentales", en Diario Constitucional, $\mathrm{N}^{\circ}$ 124, de 3 de julio de 2012, disponible en http://www.diarioconstitucional.cl/articulo-det.php?id_articulo=366\&id_cat=20. (consultado 25 de octubre de 2012)

Martínez Estay, José Ignacio (2003): "El juez y los efectos de la Constitución en el tiempo", en Revista Estudios Constitucionales (AÑO 1, № 
1). pp. 715-737.

Martínez Estay, José Ignacio (2005): "El recurso de inaplicabilidad, Tribunal Constitucional y juez ordinario en la reforma constitucional”, en Humberto Nogueira Alcalá (Coord.), La Constitución Reformada de 2005 (Santiago de Chile, Editorial Librotecnia), pp. 457-472.

MeZzETtI, LucA (2009): "Sistemas y modelos de justicia constitucional a los albores del siglo XXI”, en Estudios Constitucionales (AÑO 7, N²). pp. 281-300.

Nogueira AlcalÁ, Humberto (2003): "Tópicos sobre jurisdicción constitucional y Tribunales constitucionales", en Revista de Derecho (Volumen 14). pp. 43-66.

Nogueira Alcalá, Humberto (2005): "El control represivo concreto y abstracto de inconstitucionalidad de leyes en la reforma constitucional 2005 de las competencias del Tribunal Constitucional y los efectos de sus sentencias", en Francisco Zúñiga Urbina (Coord), Reforma Constitucional (Santiago de Chile, Editorial LexisNexis). pp. 593-626.

Nogueira Alcalá, Humberto (2010): "La sentencia del Tribunal Constitucional en Chile: análisis y reflexiones jurídicas”, en Revista Estudios Constitucionales (AÑO 8, No 1). pp. 79-116.

Nogueria Alcalá, Humberto (1995): "El Tribunal Constitucional Chileno", en Lecturas Constitucionales Andinas, ( $\left.N^{\circ} 4\right)$, (Lima, Perú, Editorial Comisión Andina de Juristas).

NúÑez Poblete, Manuel (2012): “Desaplicación e inaplicación jurisdiccional de las leyes en Chile: Ejercicio de la jurisdicción y control concreto de constitucionalidad", en Revista de DUCN. (Volumen 19, $\mathrm{N}^{\circ} 2$ ). pp. 191-236.

Pegoraro Lucio (2019): "Control jurisdiccional v.s control político: la erosión de una categoría dicotómica (y el progresivo alcance de este último), en Anuario Iberoamericano de Justicia Constitucional, (23 $\left.\mathrm{N}^{\circ} 1\right)$, pp. 43-86.

Peña, Carlos y Cea Egaña, José Luis (1996): Práctica Constitucional y derechos fundamentales. Corporación Nacional de Reparación y Reconciliación (Santiago de Chile, Editorial Santiago de Chile).

Pereira Menaut, Antonio Carlos (1999): "A Constituicao como Direito: A 
supremacía das normas constitucionaisemEspanha e nos EUA. Sobre a relacao entre o direito constitucional e o direito ordinario nasconstituicioes americana e española", en Boletín de la Facultad de Direito (Volumen 75). pp. 219-277.

Pérez Tremps, Pablo (2003): "La justicia constitucional en la actualidad. Especial referencia a América Latina”, en Revista del Foro Constitucional Iberoamericano. Instituto de Derecho Público Comparado, Universidad Carlos III. ( $\mathrm{N}^{\circ} 2$ ). Disponible en: http://www.idpc.es/archivo/1212593508a2PPT.pdf. [Consultado 30 de octubre de 2018]

Ribera Neumann, Teodoro (1989): "El Tribunal Constitucional y su aporte al desarrollo del Derecho. Aspectos relevantes de sus primeros $59 \mathrm{fa}-$ llos”, en Revista Estudios Públicos (N³4). pp. 125-228.

Ríos Álvarez, Lautaro (1988): "La Justicia Constitucional en Chile", en Revista de Derecho $N^{\circ} 1$. Facultad de Derecho, Universidad Central, Santiago, Chile.

Ríos Álvarez, Lautaro (2002): "El control difuso de constitucionalidad de la ley en la República de Chile", en lus et Praxis (Volumen 8, No 1). pp. 389-418.

Ríos Álvarez, LautARo (2005): "El nuevo Tribunal Constitucional”, en Francisco Zúñiga Urbina (Coord.) Reforma Constitucional (Santiago, Editorial LexisNexis). pp. 627-650.

Ríos ÁlvAREZ, LAUTARO (2009): "Trascendencia de la reforma constitucional en la fisonomía y atribuciones del Tribunal Constitucional”, en Revista Estudios Constitucionales (AÑO 7, N 1), pp. 73-95.

RuBio LlORENTE, FRANCISCO (1992): "Seis tesis sobre jurisdicción constitucional en Europa", en Revista Española de Derecho Constitucional (AÑO 12, No 35). pp. 9-40.

Ruiz-Tagle Vial, Pablo (1998-199): "Control constitucional concentrado y difuso: El uso de una dicotomía ruinosa", en Revista de Derecho Público de la Universidad de Chile (Volumen 61). pp. 85-95.

Saenger G, Fernando (2007): "Acción de inaplicabilidad e inconstitucionalidad. Facultad del nuevo Tribunal Constitucional. Algunos casos jurisprudenciales", en Revista Estudios Constitucionales, (AÑO 5, N¹). pp. 305-348 
Schmitt, CARL (1983): La defensa de la Constitución. (Madrid, Editorial Tecnos S.A.).

Silva IrarrázaVal, Luis Alejandro (2012): “¿Es el Tribunal Constitucional el supremo interprete de la Constitución?, Revista de Derecho de la Pontificia Universidad Católica de Valparaíso ( $\left.N^{\circ} 38\right)$. pp. 573-616.

URIBE ARZETA, EnRIQUe (2006): "Elementos para un diseño de justicia constitucional en los estados federales”, en Revista de Derecho, (Vol. 19, $N^{\circ} 2$ ). pp. 117-132.

Verdugo Ramírez, Sergio (2010): "Control Preventivo Obligatorio: Auge y caída de la Toma de Razón al Legislador", en Revista Estudios Constitucionales (Volumen 8, N 1). pp. 201-248.

ZagRebelsky (2008): La legge e la suagiustizia. (Bologna, Editorial IIMulino).

Zúñiga Urbina, Francisco y Vega, Francisco (2006): "El nuevo recurso de inaplicabilidad por inconstitucionalidad ante el Tribunal Constitucional. Teoría y Práctica", en Revista Estudios Constitucionales (AÑO 4, Nº 2). pp. 135-174.

\section{Jurisprudencia citada}

Sentencia Tribunal Constitucional Rol N 480-2006-INA, de 13 de abril de 2006.

Sentencia Tribunal Constitucional Rol N 503-2006-INA, de 15 de mayo de 2006.

Sentencia Tribunal Constitucional Rol N ${ }^{\circ}$ 546-2006-INA, de 27 de julio de 2006.

Sentencia Tribunal Constitucional Rol N 478-2006-INA, de 11 de abril de 2006.

Sentencia Tribunal Constitucional Rol N 806-2007-INA, de 27 de junio de 2007.

Sentencia Tribunal Constitucional Rol N 549-2006-INA, de 24 de julio de 2006.

Sentencia Tribunal Constitucional Rol N 790-2007-INA, de 25 de mayo de 2007 
Sentencia Tribunal Constitucional Rol N 796-2007-INA, de 06 de junio de 2007.

Sentencia Tribunal Constitucional Rol N 806-2007-INA, de 27 de junio de 2007.

Sentencia Tribunal Constitucional Rol No 1.065-2008-INA, de 24 de abril de 2008.

Sentencia Tribunal Constitucional Rol No 1.234-2008-INA, de 22 de septiembre de 2008.

Sentencia Tribunal Constitucional Rol No 1.281-2008-INA, de 05 de diciembre de 2008. 
